hibiting a dull, dusky, brick-dust hue, in place of the vivid red of ordinary conjunctivitis.

It is often observable, too, that the vascularity stops short of the corneal margin; so that between the latter and the reddened general surface of conjunctiva, a white curvilinear interval of ring is interposed. The cornea is well known to be connected with the sclerotic by an adaptation resembling that by which a watch-glass is inserted into its b.d, the bevilled margin of the cornea being received into a groove formed in the anterior edge of the sclerotic. To the outer lip of this groove, which overlays the edge of the cornea, the conjunctiva adheres more closely than to the remaining surface of sclerotic. Hence, when the conjunctiva becomes the seat of an atonic inflammation, and most of its bloodvessels, having room to dilate, become enlarged and almost varicose; this annular fillet, from its strictness of adhesion not admitting similar vascular distension, presents a comparatively nonvascular interspace-the "white ring" of arthritic inflammation. The cornea is often in old age the seat of an opaque, white zone, close to its margin, arising from a structural alteration by one observer attributed to fatty degeneration. This appearance would seem analogous to the senile changes in the coats of the vessels, the ligaments, and cartilages. Arcus senilis, by which name the affection is known, is always situate within the corneal margin, is found independently of any inflammatory condition of the eye, and is perceptible in most elderly people. It must be distingnished from the rheumatic ring just noticed, which appears at the anterior verge of the sclerotic, and being produced, as we have seen, by the abrupt transition from a highly-injected to a noninjected state of the conjunctiva, is of course only perceptible in the inflamed eye.

The aqueous membrane lining the cornea, the surface of the iris, and capsule of the lens, become dull and hazy. Sometimes the quantity of secretion in the anterior chamber is remarkably augmented; so that the iris being compressed by its accumulation, presents a concave surface anteriorly, and seems deeper than in the other eye. I have known it thus pushed back to full donble it normal distance from the cornea. The iris becomes discoloured, greenish, impaired in activity, and adherent at an early period to the capsule of the lens, which is still more apt in this than the other forms of iritis to become thickly coated with lymph, especially on a second or third attack. The discoloration and dulness of iris are general, affecting the entire superficies of the membrane; not confined to, or principally developed in, this or that spot; the fibrinous exudation, so soon produced, does not appear in isolated drops or flakes, but shows a similar tendency to uniform diffusion around the margin, and within the orifice of the pupil.

Choroiditis, amaurosis, and staphyloma of the sclerotic, are among the eventual consequences of arthritic iritis, uncontrolled and progressive. The iris is in such cases always adherent, and the pupil blocked up with false membrane. Owing to this last condition, which often exists independently of staphyloma, the iris is apt to bag forward in the interval between its ciliary attachment and the morbid adhesion, apparently from the more abundant secretion of aqueous humour at this period in the posterior than in the anterior chamber, the communication between the two cavities being intercepted.

The termination of arthritic iritis in synechia posterior and false cataract, though involving serious detriment to the organ, does not of necessity quite spoil it, if the retina continue sound; for the membrane which obstructs the pupil may not be totally opaque, and may still permit the exercise of useful vision, though it impede and reflect many rays of light which ought to have reached the nervous expansion. So mere fixity of pupil alone does not give rise to such great interference with sight as might be anticipated.

With respect to diagnosis-iritis being proved by the symptoms previously enumerated, the disease is known to be of the arthritic variety by the dull brick-dust hue of the reddened eye; the white line surrounding the cornea, wholly or in part; the diffused character of the inflammatory haziness of the anterior chamber; the early production of lymph in the pupil; the tendency to greenish discoloration of the iris; the occasional deepening of the anterior chamber, from increased secretion of aqueous humour; the dull, aching character of the pain; the age of the subject, and oftentimes his ascertained proneness to rheumatic disease. For in most cases additional evidence that the patient is subject to gout or rheumatism will be elicited upon inquiry. The latter may be pure, produced by exposure to atmospheric vicissitude, \&c., or may have resulted from gonorrhœia, or as a kind of tertiary vestige of syphilis.

\section{TWO CASES OF TRACHEOTOMY FOR THE} RELIEF OF EPILEPSY.

COM MUNXCATRD, WITH REMARKs,

BY JOHN CHARLES BUCKNILL, M.D. Lond, PHYSICIAN TO THE DEVON COUNTY LUNATIC ASYLUM.

M. G-, No. 995 , a single woman, aged twenty-two, was admitted into the Devon Asylum on the 21st of April, 1852. The master of the Union Workhouse from which she was brought stated that she was of weak intellect, and for many years had been subject to frequent and severe epileptic fits; that she had formerly lived in the workhouse, but that a year ago she was placed under the charge of a poor man at his own cottage; that this man having beaten her for breaking glass, on the morning of the Sunday previous to her admission, she escaped into the fields in a state of nudity; when recaptured, she was extremely violent; that her conduct was habitually violent, and her habits dirty. No history of her early life could be obtained. On admission, she was in the state of extreme and motiveless rage which is seldom observed except in cases of epileptic mania. Her head and features were well shaped, and did not indicate the existence of idiocy; this observation was confirmed by the considerable selection of epithets and command of language which she was found to possess. The head was over-warm; tongue coated; desire for food good; pulse 104, deficient in fulness; sleep sound. The lower incisor teeth had been removed, probably to prevent the infliction of injury by biting. The catamenial function was found to be torpid; for this electro-galvanism was prescribed, but had to be discontinued in consequence of the extreme restlessness its application produced. The epileptic attacks were heavy and frequent, leaving, however, periods of a week, or two weeks, during which she was free from them. The convulsions of the limbs were not severe, but the respiration was completely interrupted; the face became darkly livid, and the coma was deep and long.

The treatment adopted-namely, moderate aperients, the frequent application of two or three leeches behind the ears, morning shower-baths, \&c.- - appeared to afford some transient relief. In November last, maniacal excitement was extreme; the patient attempted self-destruction, by lacerating the rectum and the vagina with her fingers. She lost a good deal of blood in this and in similar attempts of the same nature. She avowed a suicidal intention. In January of the present year, the fits became more frequent, and the periods during which they had been accustomed to intermit ceased to occur. She generally had four or five severe attacks during the twenty-four hours. Under the influence of these constantly recurring convulsions, her temper became more vicious than ever. With blind fury she attempted to bite, kick, and strike all around her; and it required all the ingenuity and watchfulness of the attendants to prevent unpleasant results. When capable of answering inquiries, she complained of great pain in the vertex. In the hope of alleviating these symptoms, ten grains of nitrate of silver was given daily for three months, without, however, producing any appreciable change. In the severity and frequency of the fits, and the gravity of the maniacal excitement which accompanied them, this case equalled, if it did not surpass, any similar ones which has been treated in this institution. Matters continuing, if possible, to get worse, it was determined to give the patient the chance of relief afforded by tracheotomy.

The operation was performed on the 2 nd of Miny last. The patient was put under the influence of chloroform. The opening into the trachea was made below the isthmus of the thyroid body, which was hypertrophied; the trachea lay at a great distance from the surface, in consequence of an hypertrophied condition of the sterno-mastoid muscles-a condition which $I$ have frequently observed in those long subject to epilepsy. The incisions were made in a vertical direction. On recovering from the influence of the chloroform, the patient became so violent, that it was found to be impossible to retain the canula in the wound. After many ineffectual attempts to do so, and anxious not to lose the benefit of the operation on this account, I removed a semicircular portion of the trachea on each side of the incision, with the intention of establishing a fistulous communication without the aid of a canula, In the night she had a severe fit, the wound being plugged up with lint to prevent oozing. On the 6 th she had two slight fits, not becoming as usual black in the face or frothing at, the mouth during recovery. Since her admission she has not had a slight fit before. On the 7 th and 8 th she had three seyere fits, the opening into the trachea having become 
obstructed with exudation. It was cleaned, and soon afterwards she had a slight fit. From this time up to the present date great difficulty has been experienced in keeping the fistulous communication open. The size of the sterno-mastoid muscles and of the thyroid body make the fistula a long one. The incisions having been made parallel to the muscula fibres and across the skin folds, the tendency to close has been great. This tendency, after the failure of milder measures, has only been obviated by the use of potassa fusa. This escharotic has been used three times. During the time that the fistula has been closed by the slough thus produced, the patient has had two severe fits; after the fistula has become open again, the fits have been slight. Since the operation has been performed the temper and conduct of the patient has undergone a great and remarkable change for the better. She is at times sullen, and at other times perverse; but her behaviour resembles the haughtiness of a self-willed child rather than the extreme fury of epileptic mania, which had for so long a time been its characteristic. Her general health has improved. Up to the present time $I$ think it a moderate and impartial estimate to say that since the operation her fits have declined fifty per cent in frequency, and seventy-five per cent. in severity.

C. C- (No. 497,) a single woman aged thirty-five, was admitted into the Devon Asylum, Feb. 2nd, 1848. Had been subject to epileptic attacks for seven years at least; had been a domestic servant until three years ago, when she was compelled to relinquish occupation on account of the increasing strength and frequency of the fits. At first the fits were isolated and rarely occurred during the day time, but of late years they have become numerous. During the latter time her character has become much changed, more especially during the epileptic period, which is frequently contemporaneous with the catamenial flow. She is generally slow, heavy and fond of bed; at other times she is violent and unmanageable, screaming, striking, refusing food, and threatening to destroy herself.' The canse of disease is unknown. No other members of the family are epileptic or subject to nervous disorders. On admission, the skin was dry; head hot bowels confined; pulse quick and of good strength; functions of uterus regular; sleep disturbed; tongue broad, pale, and has been severely bitten. Her intellects were found to be dull, and in reading she frequently miscalled words; formerly she could read well: she was good-tempered and quiet cleanly in her habits, and willing to be employed. The various entries in the case-book, from the date of her admission to the spring of 1851 , show, that in the intervals of the epileptic periods she was quiet, obliging, and industriously employed in the laundry or wards. The fits did not come on periodically, although a number of them occurred about the same time. Before they came on she was heavy and stupid for a few days; they were accompanied sometimes by maniacal excitement, sometimes by tendency to suicide, sometimes by dread of death. No aura or warning occurred before them, and, contrary to the common rule, when a fall took place it was always a backward one, and the blow was received on the occipnt. By wearing a bonnet with padding in the crown the force of such blows was greatly diminished. The character of the fits was severe. The convulsive movements were not general, but the respiratory were entirely suspended. The face became very livid, and when the spasm relaxed froth accumulated round the mouth. Medical treatment appeared to mitigate the attacks, but the amelioration was not permanent, and, on the whole the condition of the patient slowly but gradually deteriorated. In March, 1851, the patient was one of seven on whom sumbul was tried. During the month she was taking it she had nineteen fits; in the following month, when this medicine was omitted, she had only twelve.* On the 20th of June, the operation of tracheotomy was performed. Chloroform produced so much irregularity in the respiratory movements, that it was deemed advisable to allow its effects to pass off before the operation was proceeded with. The incisions were made transversely, and a large canula was placed in the trachea, just below the cricoid cartilage. Subsequently to the operation the patient has had seven fits; their character is entirely changed; there is not the slightest lividity of the face or frothing at the mouth. Each fit is recognised by a convulsive movement of the eyes, and by slight twitchings of the arms and facial muscles. The state of unconsciousness continues about half a minute, leaving behind a very moderate degree of stupor, which passes off in

* Averaging the cases on whom the sumbul was tried, it neither increased nor diminished the number of the fits. half an hour. In language current in the wards " the fits flutter off." She is not only tranquil, but is cheerful and thankful for her improvement. The canula is kept in its place withont difficulty, and the opening is free enough to permit the whole of the respired air being passed through it at the will of the patient.

On these cases I shall take leave to make a few remarks, surgical and medical. The first was certainly undertaken with little hope of a successful result. But under the aggravated circamistances presented by it, the operation appeared to be a justifiable pis aller. It has certainly ameliorated the distressing condition of the patient in a far greater degree than a cantious prognosis would have permitted one to hope for. The improvement of the patient's temper is a noteworthy occurrence; it is a change of no slight or doubtful nature, but obvious and decided. A fit has several times occurred, when the deep and narrow fistula has become almost closed by fibrinous exudation, or by a slough caused by the use of an escharotic. At such times the fits have had their old characters of apnœa and coma, and the patient has for some hours afterwards become violent. When the fistula became free the symptoms were ameliorated. These facts afford proof of the relation in which the phenomena stand to each other-a proof arrived at by the method of agreement and that of difference, and therefore logically complete. The surgery of this case, however, must be considered imperfect and unsatisfactory. It was an error to make the incisions below the thyroid body, and in a line with the axis of the trachea. This operation may be the best for the removal of foreign substances from the air passages when the opening is intended to be speedily closed.

In operations also for diseased larynx it may be necessary to make the incisions low in order to remove them as far as possible from the seat of the disease; but for the present purpose the low operation is decidedly ineligible, on account of the great proneness which such wounds have to close.

Liston, writing on tracheotomy, states:-_"The union and cicatrization of such longitudinal wounds are soon accom. plished; they close permanently in a few days, even after having been open for many weeks with a foreign substance interposed between their edges. The same obstacles do not interfere as in transverse wounds; on the contrary, every circumstance is in favour of rapid union." - (Elements of Surgery, p. 451.)

The operation for epilepsy supposes the necessity for the wound remaining permanently open, inasmuch as the cure of the disease is not attempted or expected; and the remission of its graver symptoms can only continue so long as the artificial opening remains free. 'The incisions therefore will best answer this purpose which will remain open with the least trouble and the greatest certainty.

Another reason for preferring the higher operation is the depth at which the lower part of the trachea lies from the surface. This depth is always enough to increase the diffculties, but in epileptic patients the trachea often lies much deeper than usual, in consequence of the hypertrophied condition of the muscles in those parts. Influenced by these considerations, in the second case I made the incisions above the thyroid body and in a transverse direction, dividing the muscular fibres freely, and laying bare the trachea just below the cricoid cartilage. The main incision into the trachea was also made transversely, but from the middle of the lower edge a short downward incision was added. The result has been satisfactory. In the first case an imperfect supplemental inlet only was effected, and the respiration was but partially relieved during a fit. In the second case a full and sufficient passage was afforded for all the air required, and during the fits the respiration is not impeded in the slightest degree.

Notwithstanding the relief afforded to both the above cases, and to several others which have been recorded, it is highly probable that in many cases of severe epilepsy the operation would fail from causes which have not hitherto been sufficiently examined. Where the symptoms of severe epilepsy depend upon spasmodic closure of the laryngeal opening, tracheotomy will probably afford all the relief which has been promised. If, however, severe epilepsy may occur independently of what is now called laryngismus, in such cases the operation will be resorted to in vain. It is with much diffidence that on this point I venture to express an opinion at variance with that of the distinguished physician, to whose genius we owe so much enlightenment on the pathology of these diseases, and who has added the final crown to his work by teaching this application of surgery to the relief of what has so long been the opprobrium medicorium. A man, however, who has for many years lived under the same roof with 
from fifty to sixty epileptic patients may be excused for being a little positive respecting the symptomatology of the affection. On such grounds I hold my opinion that, although laryngismus is generally an emphatic symptom, a main cause of cerebral disturbance, and a frequent cause of death in epilepsy, yet that severe cases do not unfrequently occur in which the laryngeal spasm is slight or altogether absent. During the present week, I have attended a man who died exhausted after two days spent in recurring fits. The muscles of the limbs and the trunk were strongly convulsed, but there did not exist the slightest indication of laryngeal sp.ssm. During each fit the respiration became slow, apparently owing to spasm of the thoracic muscles. The chest was held open at the extreme point of dilatation during five or six seconds. It was, however, obvious that no impediment existed to the ingress or egress of air through the larynx. Of course, under such circumstances tracheotomy would be useless. It would also be useless in other instances wherein the respiration is to a much greater extent interfered with by spasm of the thoracic muscles and diaphraghm. This latter condition may prevent its beneficial application for the relief of tetanic symptoms; for it should be remembered that, although a man may be asphyxiated by ligatures round the abdomen and chest, as certainly as by one round the throat, in the latter predicament only could tracheotomy let in the vital air.

Severe epileptic convulsions occasionally confine themselves to the limbs, leaving the larynx and the thoracic muscles unaffected. I have endeavoured to verify the observations made in such instances by sight and palpation by the use of Dr. R. Quain's stethometer; but the violent movement of the limbs prevented a satisfactory application of this ingenious instrument to so rough a purpose.

It would appear, therefore, that the convulsive movements in epilepsy are by no means so regular and uniform in site and degree as many persons suppose. Omitting premonitory signs, the symptoms develop themselves in the following sequence: 1 , loss of conscionsness; 2 , convulsive movements; 3, coma. Of these it may be said that the sudden and peculiar loss of consciousness is alone essential to and characteristic of the disease.

This complete interruption of cerebral action, equally distinct in character from syncope and coma, constitutes the punctum saliens of this obscure disorder. Attempts to explain this condition have been insufficient, or have become lost in speculations on cerebral electricity and the polarity of the brain corpuscles. Its ultimate cause and nature may perhaps long remain shrouded in the mystery which veils the union of consciousness with cerebral action. The convulsive action is a secondary phenomenon, the gross amount of which serves as a basis for the coarse classification of the disease into two varieties; its nicer peculiarities have not yet been sufficiently studied.

That epileptic loss of consciousness may habitually occur without convulsive movement of any kind is a fact of which several unambiguous examples have come under my own observation. Between this condition and the other extreme, wherein convulsive movements have dislocated the lower jaw broken the teeth and limbs, (which occurrences are recorded on credible authority,) every degree and almost every variety of convulsive movement may take place. The whole system of voluntary and semi-voluntary muscles may be affected in portions or in its entirety; but the muscles subservient to the function of respiration are alone capable by their spasmodic contraction of producing results immediately and greatly detrimental to the vital economy. Hence arises the vast importance of laryngeal and thoracic spasm, and the value of tracheotomy as a means of relief from the apnœa and coma dependent upon the former; the latter being an auxiliary, but never (within the scope of my own observation) being a principal means of producing these conditions.

In some instances of severe epilepsy, wherein the laryngeal muscles are not affected, the frequent repetition of convulsions may exhaust the nervous energy, and the patient may die from asthenia.

Coma, however, must be considered the true tertiary symptom and the ordinary source of danger in this disease. That it is caused by, and commensurate with, spasm of the muscles, subservient to the function of respiration, can admit of little doubt. It is, however, often confused with a very different cerebral condition - namely, the state of stupor which succeeds the epileptic shock. A certain amount of intellectual dulness succeeds the petit mal when little or no convulsion has taken place. This condition resembles one of imperfect concussion, and lasts while the brain recovers itself from the shock. During its continuance the patient is dizzy, the faculties are confused, but consciousness exists. Coma depending upon deficiency of duly oxygenated blood is quite different thing.

If the above views are correct they will assist in the selection of cases favourable for the performance of tracheotomy, and may serve to prevent a valuable remedy from incurring partial failure and disrepute from want of discrimination in its use.

In what proportion of epileptic patients the laryngeal spasm forms a prominent and formidable symptom remains to be ascertained. This information will not easily be procured, because in order to form a sound judgment thereupon it will be necessary for the medical inquirer to see the early stages of a fit in each patient; a necessity which will demand an amount of attendance which, even in hospital practice, it will be difficult to bestow, and which in private practice will be impossible. Except to relieve a patient from impending death from coma, a physician would scarcely be justified in recommending a serious operation in this disease, until he had obtained opportunities for observing all its symptoms; yet he may diligently attend a patient afflicted with epilepsy for a very long period, without chancing to see the accession of a single fit.

Dr. Marshall Hall, in the list of cases to which he considers the operation inapplicable, includes those complicated with insanity. It is probable that insanity is more frequently produced by cerebral congestion and coma than by any other of the symptoms whose aggregate we name epilepsy; therefore it is probable that insane epileptics would include a larger proportion of laryngismus cases than other epileptics not insane. Moreover, cases thus complicated are of the most deplorable nature. Hitherto they have baffled medical science and are considered hopelessly incurable. The employment of heroic measures for their relief is consequently more justifiable than in less serious forms of the disease. In cases of uncomplicated epilepsy it may well deserve consideration, whether the gravity of the symptoms counterbalances that of the operation and its consequences, interferes with the vocal powers, and other inconveniences which it is needless to enumerate. If not, the patient may, after all, choose to prefer the fits, and allow the opening to close. An artificial breathing hole in the front of the throat kept constantly open and free is a remedy which patients are not likely to maintain unless the symptoms it obviates are truly severe. Therefore, without reason shown to the contrary, it would appear that the more formidable any case of epilepsy is in itself, or in its results, so much the more desirable and necessary will be the operation of tracheotomy for its relief.

Perhaps these considerations, and the success of the foregoing cases will induce Dr. Marshall Hall to reconsider his judgment on this point. The great majority of epileptics become insane, and the benefits of his discovery wouid be greatly restricted if the complication of epilepsy with insanity was found to be any barrier to its use.

August, 1853.

\section{REMARKS ON YELLOW FEVER.}

Bx JAS. PATON, Esq., M.R.C.S. Eng., Kingston, Jamaica.

That fearful scourge, the yellow fever, paid us a visit here in November last, and still continues our unwelcome guest. During this period its effects have been dreadfully fatal, the deaths amounting to no less than seventy-five per cent. I now allude to the cases attended in my own practice; but I do not think my prother practitioners can give a more favourable report, excepting in the Public Hospital, where I am told the mortality was not greater than forty-eight per cent, although, strange to say, much the same plan of treatment was adopted. For some time the disease was entirely confined to the shipping in the port; but of late it has made its appearance in the city in an equally severe type, although it does not seem inclined to spread in the latter to the extent that it has done in the former. 'The first cases of yellow fever that were seen here in the present epidemic were on board the Royal Mail Steam-Packets; they contracted the disease at St. Thomas', and brought it down here with them. At this time it was almost entirely confined to those vessels, and did not spread amongst the other shipping. In March last a ship, called the William Jardine, arrived here from Demerara, where the disease was existing when she left; some of her crew were attacked after leaving that port, and one man died on the passage. After her arrival here the disease spread 